Earth System Dynamics

Supporting Information for

\title{
Climate Change Projections of Terrestrial Primary Productivity over the Hindu Kush Himalayan Forests
}

\author{
Halima Usman ${ }^{1}$, Thomas A.M. Pugh ${ }^{2}$, Anders Ahlström³ ${ }^{3}$ Sofia Baig ${ }^{1 *}$ \\ ${ }^{1}$ Institute of Environmental Sciences \& Engineering, National University of Sciences and \\ Technology, Islamabad, 44000, Pakistan \\ ${ }^{2}$ School of Geography, Earth and Environmental Sciences, University of Birmingham, \\ Edgbaston, Birmingham, B15 2TT, UK \\ ${ }^{3}$ Department of Physical Geography and Ecosystem Science, Lund University, Lund, SE-221 00, \\ Sweden
}

Correspondence to: Sofia Baig (e-mail: sofia.baig@iese.nust.edu.pk) 


\section{Introduction}

Net Biome Productivity (NBP) is an important measurement of flux which assesses if the region is acting a net sink or net source of carbon. Simulated NBP by IPSL-C5A-MR reveals an increasing trend for the period 1951 to 2005 with a mean NBP of $0.0035 \pm 0.018 \mathrm{~kg} \mathrm{C} \mathrm{m}^{-2} \mathrm{yr}^{-1}$. The NBP of future scenario under RCP2.6 was estimated to be $0.0029 \pm 0.05 \mathrm{~kg} \mathrm{C} \mathrm{m}^{-2} \mathrm{yr}^{-1}$ and $0.0039 \pm 0.07 \mathrm{~kg}$ $\mathrm{C} \mathrm{m}^{-2} \mathrm{yr}^{-1}$ under RCP8.5 (Figure S1). For MPI-ESM-LR, a similar trend was also observed, with average NBP of $0.02 \pm 0.04 \mathrm{~kg} \mathrm{C} \mathrm{m}^{-2} \mathrm{yr}^{-1}$ and $0.04 \pm 0.06 \mathrm{~kg} \mathrm{C} \mathrm{m}^{-2} \mathrm{yr}^{-1}$ under RCP2.6 and RCP8.5 respectively (Figure S2). Most of the carbon sink capacity in the HKH rises in the Tibetan region of China where mostly grasslands are located. With increasing $\mathrm{CO}_{2}$ concentration, the $\mathrm{CO}_{2}$ fertilization

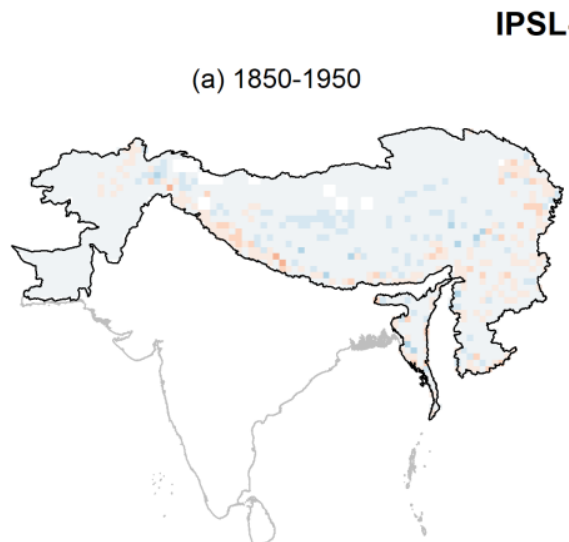

(c) $2006-2100$ (RCP2.6)

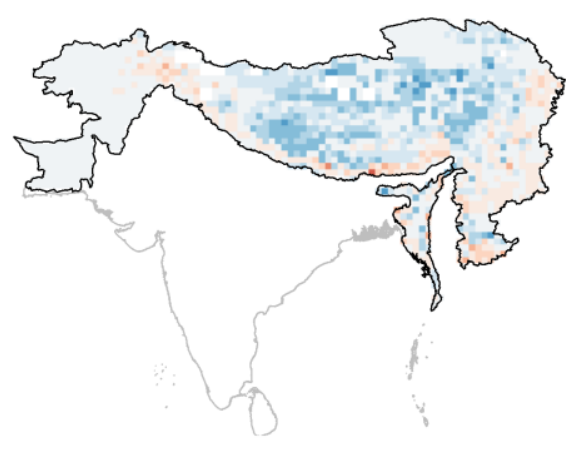

(b) $1951-2005$

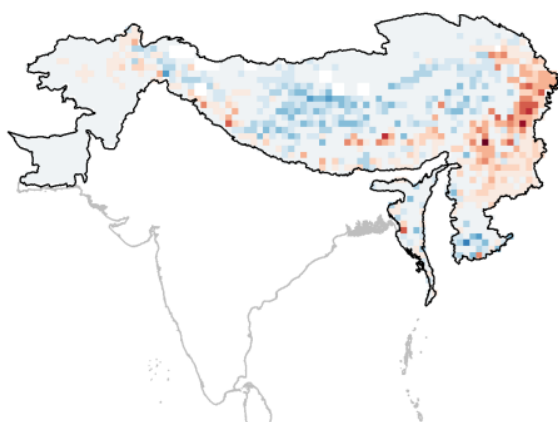

(d) 2006-2100 (RCP8.5)

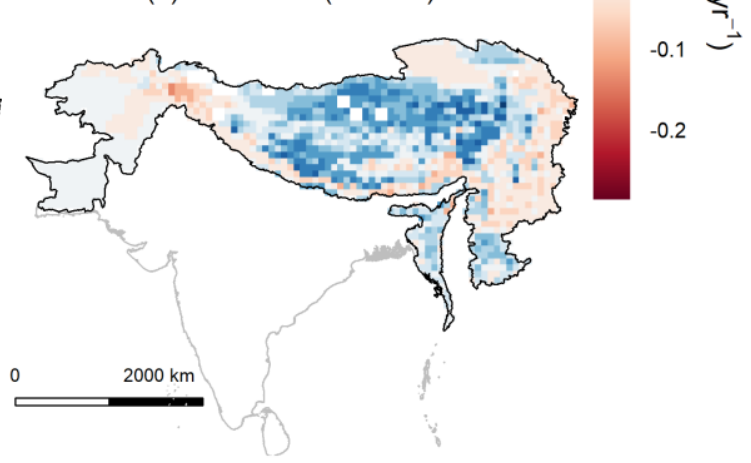

Figure S1: LPJ-GUESS simulated distribution by IPSL-CM5A-MR on NBP in HKH region under a) past period (1850-1950) b) present period (1951-2005) and future scenario under c) RCP2.6 scenario and d) RCP8.5. 
(a) $1850-1950$

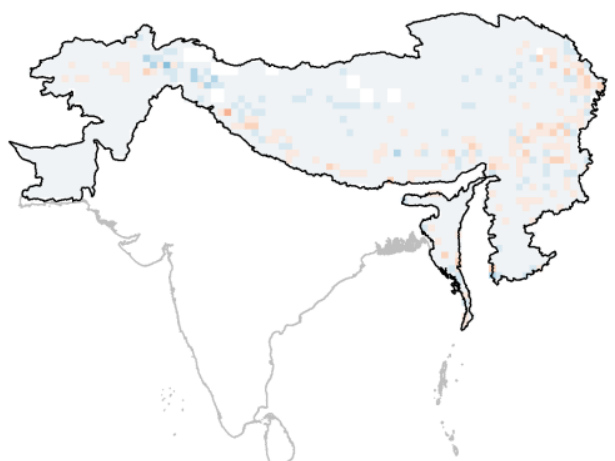

(c) $2006-2100$ (RCP2.6)

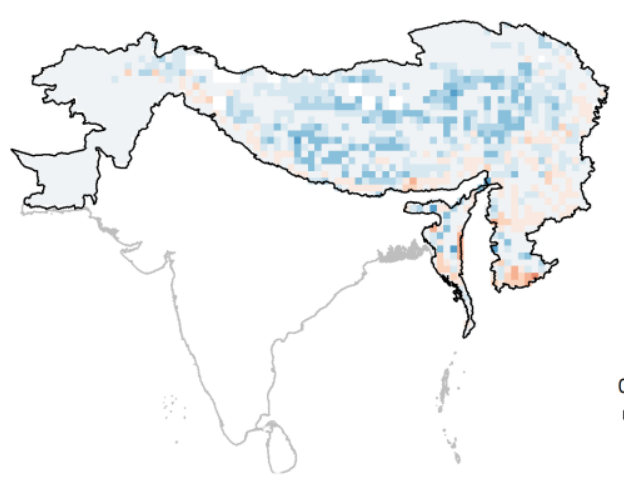

(b) $1951-2005$

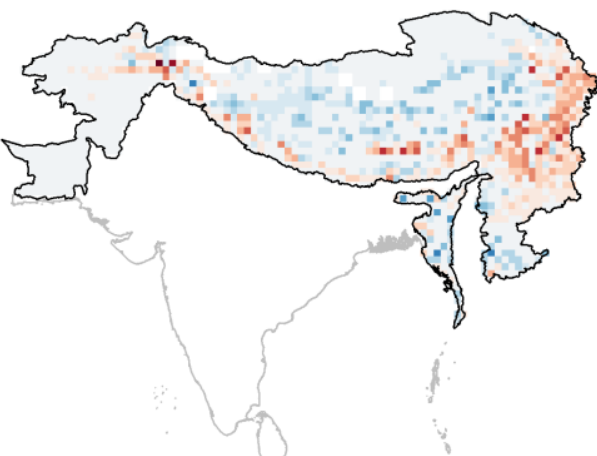

(d) $2006-2100$ (RCP8.5)

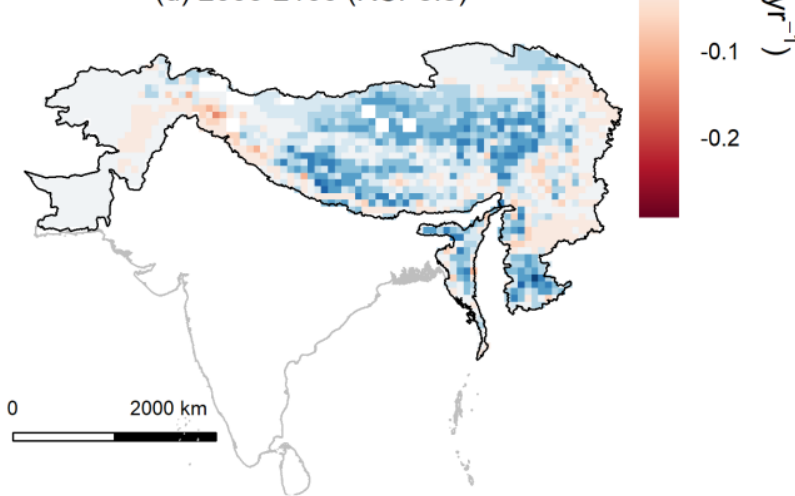

Figure S2: LPJ-GUESS simulated distribution by MPI-ESM-LR on NBP in HKH region under a) past period (1850-1950) b) present period (1951-2005) and future scenario under c) RCP2.6 scenario and d) RCP8.5. 
The mean spatial VegC for IPSL-CM5A-MR was estimated to be $2.61 \mathrm{~kg} \mathrm{C} \mathrm{m}^{-2}$ from 1850-1950, and $2.10 \mathrm{~kg} \mathrm{C} \mathrm{m}^{-2}$ from 1951-2005. Under the future scenarios RCP2.6 and RCP8.5 the VegC was estimated to be $2.12 \mathrm{~kg} \mathrm{C} \mathrm{m}^{-2}$ and $2.61 \mathrm{~kg} \mathrm{C} \mathrm{m}^{-2}$ respectively (Figure S3). Furthermore, for MPIESM-LR, the VegC was estimated to be $2.83 \mathrm{~kg} \mathrm{C} \mathrm{m}^{-2}$ from $1850-1950$ and reducing to $2.22 \mathrm{~kg} \mathrm{C}$ $\mathrm{m}^{-2}$ from 1951-2005. Under the RCP2.6 the VegC is predicted to be $2.24 \mathrm{~kg} \mathrm{C} \mathrm{m}^{-2}$ and $2.80 \mathrm{~kg} \mathrm{C}$ $\mathrm{m}^{-2}$ under RCP8.5 scenario.

\section{IPSL-CM5A-MR}

(a) $1850-1950$

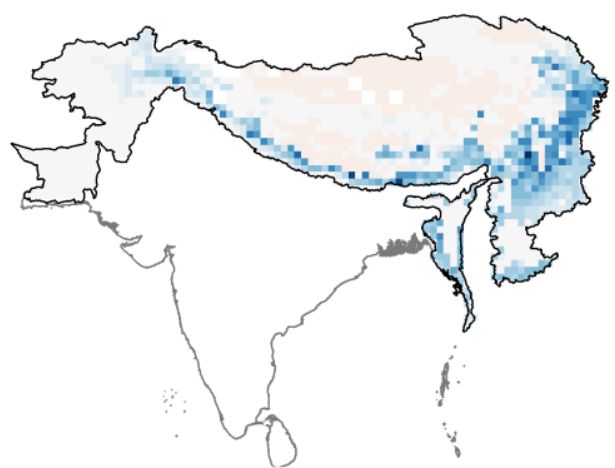

(c) $2006-2100$ (RCP2.6)

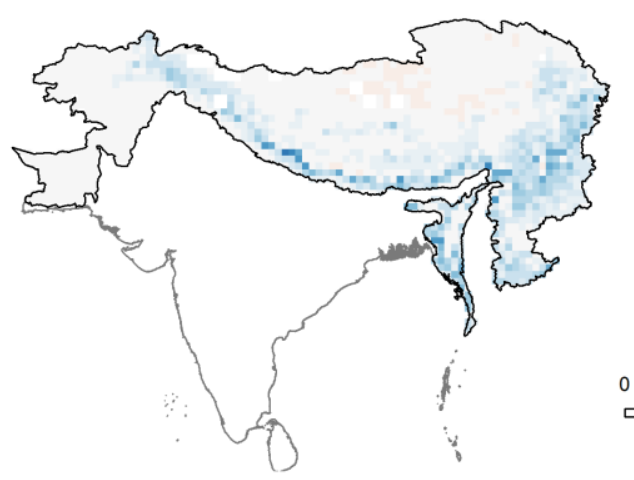

(b) 1951-2005

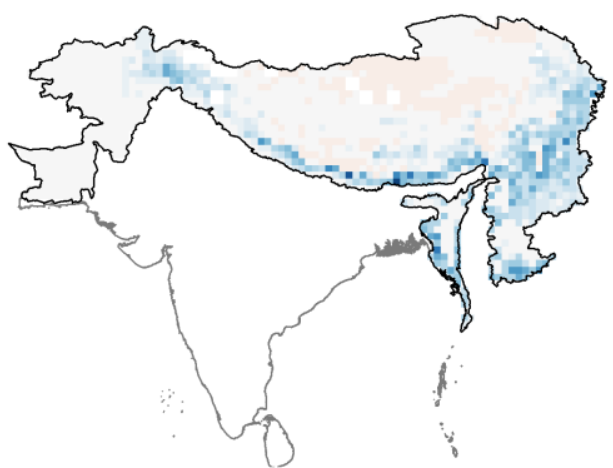

(d) $2006-2100$ (RCP8.5)

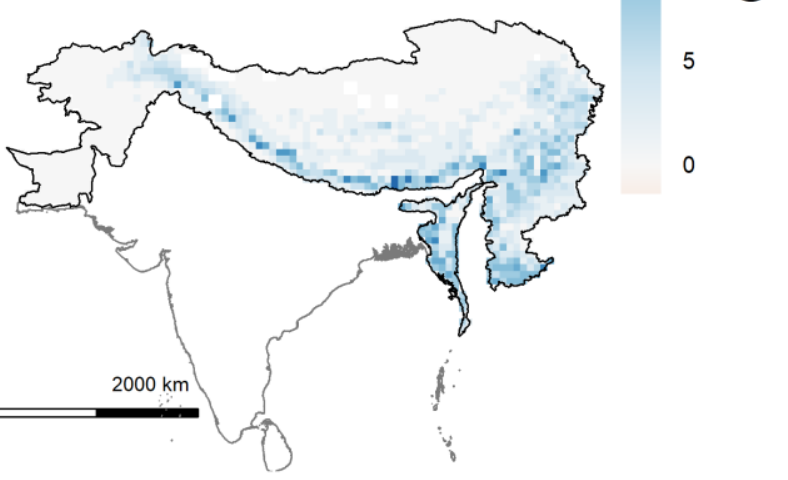

Figure S3. LPJ-GUESS simulated distribution by IPSL-CM5A-MR of VegC in HKH region under a) past period (1850-1950) b) present period (1951-2005) and future scenario under c) RCP2.6 scenario and d) RCP8.5. 
(a) $1850-1950$

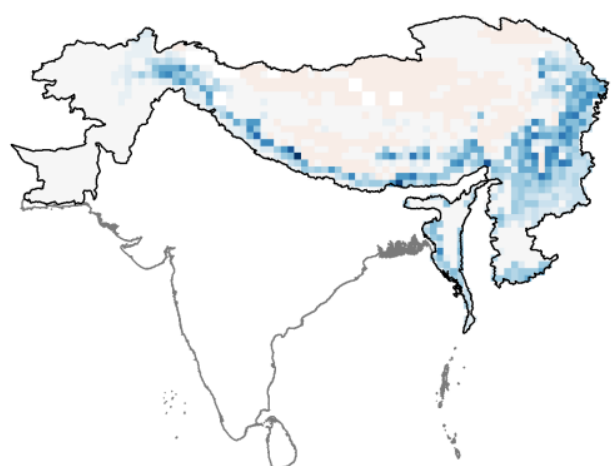

(c) $2006-2100$ (RCP2.6)

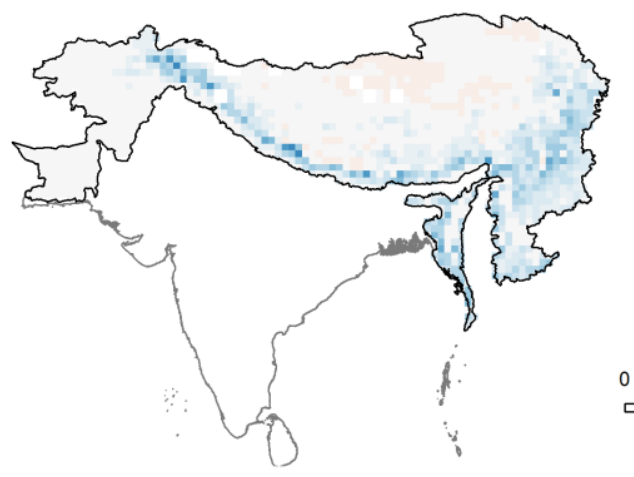

(b) $1951-2005$

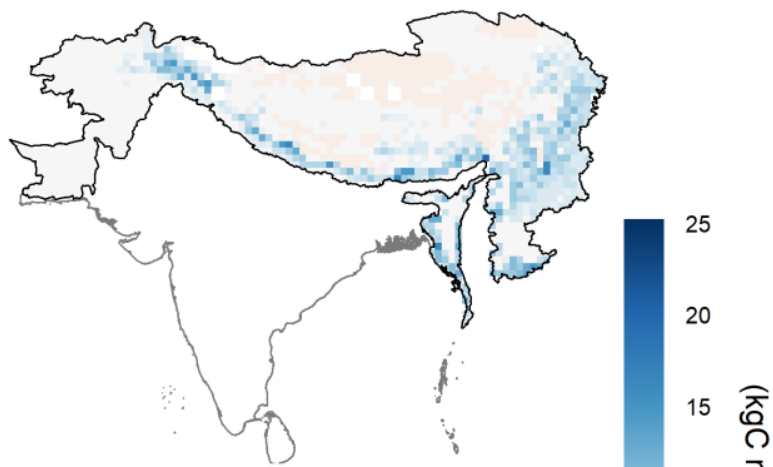

(d) 2006-2100 (RCP8.5)

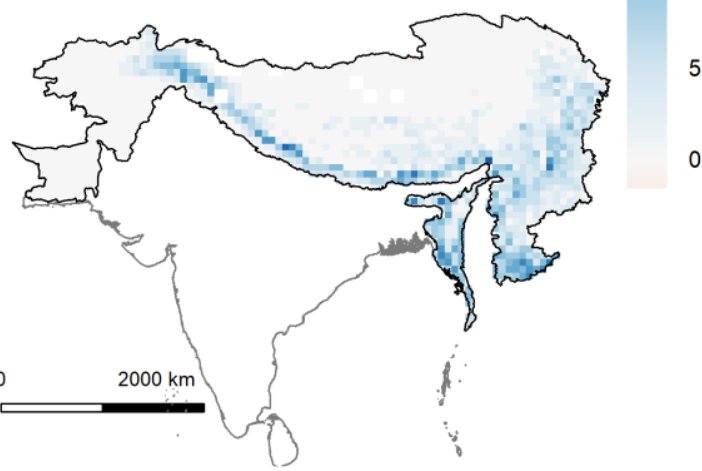

Figure S4. LPJ-GUESS simulated distribution by MPI-ESM-LR of VegC in HKH region under a) past period (1850-1950) b) present period (1951-2005) and future scenario under c) RCP2.6 scenario and d) RCP8.5. 